\title{
Broadband Antenna for LTE Operation: A Novel Design Approach Using Meandered Strip Line
}

\author{
M. Kumaran \\ M.E. Communication Systems, Sri Venkateswara College of Engineering, India
}

\begin{tabular}{l}
\hline \hline Article Info \\
\hline Article history: \\
Received March 10, 2015 \\
Revised May 18, 2015 \\
Accepted May 26, 2015
\end{tabular}

Keyword:

Broadband antenna

LTE 22 band

LTE 42 band

Meandered antenna

Monopole

\begin{abstract}
The broadband performance of an antenna for the LTE operation is presented in this paper. A novel design approach used to design the antenna using meandered strip line can be treated as a simplest and a cost effective approach. Due to the requirement of the bandwidth hungry applications, there is a smooth migration of the mobile technology from the existing services like GSM; UMTS to LTE is in progress. Thus a compact radiating structure can be preferred in many applications to improve the throughput performance of the multimedia service. The proposed antenna operates in the LTE 42 band. It shows the broadband performance centred at $3533 \mathrm{MHz}$ with $112 \mathrm{MHz}$ bandwidth. Bandwidth performance at this frequency is also found to be well suited to operate in the downlink frequency band at LTE 22. To determine the optimal performance of the antenna, a suitable threshold $\left(\mathrm{S}_{11}<10 \mathrm{~dB}\right)$ is imposed. Gain and directivity of the antenna are $6.6 \mathrm{~dB}$ and $7.8 \mathrm{dBi}$ respectively. Efficiency is achieved to $74 \%$. Radiation pattern shows the best performance of the antenna. With the best performance achieved at this frequency, the antenna is advantageous to exploit in small cell coverage, LTE Hotspot and Indoor enhancement solutions. CST Microwave Studio Suite software is used to design the antenna. An ordinary $50 \Omega$ transmission line is fed to the antenna. Other antenana parameters are also discussed for its performance.
\end{abstract}

Copyright () 2015 Institute of Advanced Engineering and Science. All rights reserved.

\section{Corresponding Author:}

M. Kumaran,

M.E. Communication Systems,

Sri Venkateswara College of Engineering,

Sriperambudur, India.

Email: kumarandocuments@gmail.com

\section{INTRODUCTION}

Growth in the demand for the wireless communication and information transfer using handsets created the need for advancement of antenna design as a fundamental part of any wireless systems. Since its evolution, different antennas ranging from simple to complex structures from the earily generation to the fourth generation $(4 \mathrm{G})$ have been in use that are intended for various applications depending on the service the communication system provides. Focusing on the second generation $(2 \mathrm{G})$ through fourth generation $(4 \mathrm{G})$ mobile technology, simple, light-weighted, low profile, and cost efficient antenna is being preferred. Emphasizing all, the microstrip patch antenna with different structure suitable for the $2 \mathrm{G} / 3 \mathrm{G}$ and $4 \mathrm{G}$ LTE service is proposed [1-6]. Further, an approach of using the meandered strip line in the antenna design reduces the overall size of the antenna. A wideband performance is achieved in the meandered monopole antenna design when it is surrounded by the parasitic strips provided the sleeve feed [3]. Eletrically small antenna designed with meandered line section provides dual band performance suitable for wireless application [4].

Some paper proposes solutions for mutal coupling when the antenna is designed for MIMO application. When the two port signals are orthogonally polarized then the coupling effect can be redued [5]. 
Integrating a LC-based branchline hybrid coupler with the designed dual element array antenna provides necessary isolation and decouples the port [6]. Some structure follows atmost complex algorithm to determine the optimal parameters in the antenna design. Monopole antenna design based on the planar sierpinski fractal shape has the triangular shape [7] and the circular shape [8]. A combination formed by the loop pattern and device chassis along with the monopole like structure enables the multiband excitation [9]. Additionally [10] examine and propose that the branched strips introduced in the horizontal and vertical position to the meandered antenna provide dual-band performance suitable for WLAN systems.

Considering all the advantages of microstrip, a simple meandered line structure is proposed in this paper. Operating in LTE 42 / LTE 22 downlink region, the antenna is also found suitable to exploit in LTE Hotspot, Indoor enhancement solutions and to cover small cells. Emphasizing the operational band and centred frequency of the designed antenna, $3500 \mathrm{MHz}$ is considered to be one of the most important bands of global spectrum for small cell [11]. Thus the antenna operating in this band finds its trend in the traffic offloading requirement. Desin specification and the broadband performance of the antenna is discussed in section 2. Section 3 is conclusion.

\section{DESIGN SPECIFICATION}

Proposed structure of the antenna is the combination of standard monopole and the meandered line section. Figure $1 \mathrm{a} \& \mathrm{~b}$ shows the geometry of the proposed antenna and the designed antenna. Copper metallic layer is structured on Arlon AD 320 substrate with $\varepsilon_{\mathrm{r}}=3.2$ and $\tan \delta=0.0038$. Height of the substrate is $1.6 \mathrm{~mm}$. Antenna dimension $\left(\mathrm{L}_{\mathrm{g}} \times \mathrm{W}_{\mathrm{g}}\right)$ measures $75 \mathrm{~mm} \times 104 \mathrm{~mm}$. A $50 \Omega$ transmission line is used to feed the antenna.

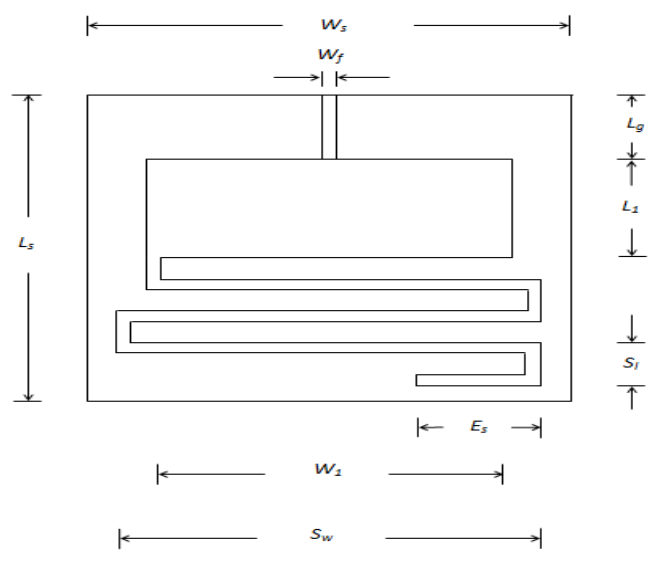

(a)

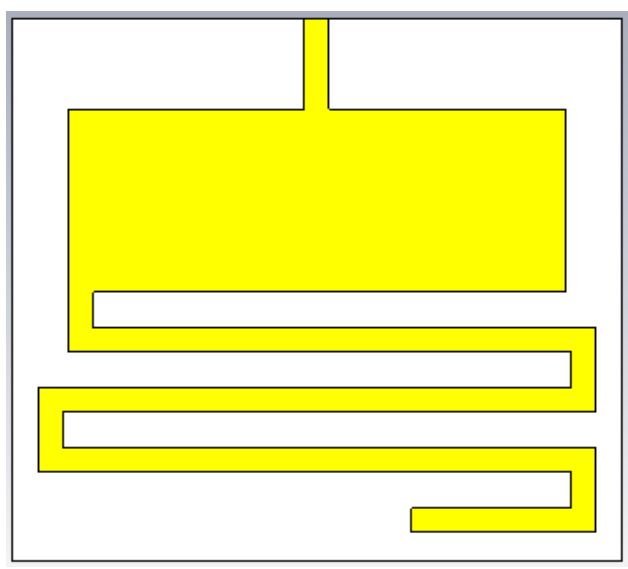

(b)

Figure 1. (a) Geometry of the proposed antenna, (b) Designed structure

$\mathrm{L}_{1}, \mathrm{~W}_{1}, \mathrm{~S}_{\mathrm{W}}$, and $\mathrm{S}_{1}$ are the key parameters to be focused for the impedance bandwidth, radiation and frequency tuning. Space between the meandered strips is $5.9 \mathrm{~mm}$. Length of the meandered line is $245.3 \mathrm{~mm}$ (approximately) when unfolded. Use of the meandered strip allows the current flow providing longer resonance path at the operating frequency [10]. Specific values of all the design parameters of the antenna are listed in Table 1. Figure 2 shows the simulation return loss for the proposed antenna. Usual threshold $S_{11}<10$ $\mathrm{dB}$ is imposed to determine the optimal performance of the antenna. Bandwidth of $112 \mathrm{MHz}$ is achieved with the centre frequency $3533 \mathrm{MHz}$. Return loss $\mathrm{S}_{11}<10 \mathrm{~dB}$ is minimum with $26.45 \mathrm{~dB}$ at the corresponding frequency. Showing the reasonable return loss, the antenna radiates efficiently at this frequency with the efficiency of 74\%. Table 2 shows the details of bandwidth allocated for LTE 42 band / LTE 22 downlink frequency and the bandwidth obtained for the designed antenna in that band.

Table 1. Design values for the proposed meandered antenna

\begin{tabular}{cccccccccc}
\hline Parameters & $\mathrm{L}_{\mathrm{s}}$ & $\mathrm{W}_{\mathrm{s}}$ & $\mathrm{L}_{1}$ & $\mathrm{~W}_{1}$ & $\mathrm{~S}_{\mathrm{w}}$ & $\mathrm{S}_{\mathrm{l}}$ & $\mathrm{E}_{\mathrm{s}}$ & $\mathrm{W}_{\mathrm{f}}$ & $\mathrm{L}_{\mathrm{g}}$ \\
\hline $\begin{array}{c}\text { Dimensions } \\
\mathrm{mm}\end{array}$ & 75 & 104 & 21.8 & 58.5 & 68.5 & 12.5 & 21.2 & 3.3 & 14.1 \\
\hline
\end{tabular}




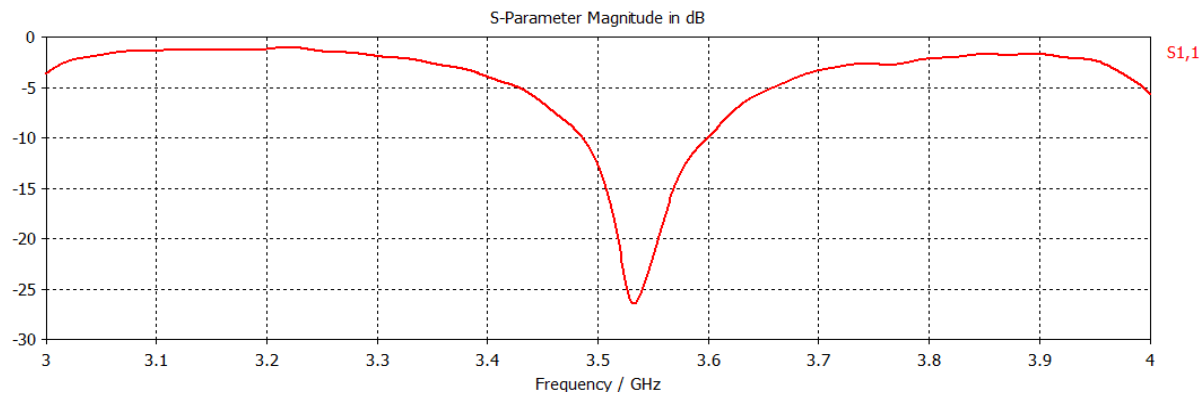

Figure 2. Simulation return loss of the proposed antenna

Table 2. Details of bandwidth allocation and the obtained bandwidth of the proposed LTE antenna

\begin{tabular}{ccccc}
\hline Band & $\begin{array}{c}\text { Allocated } \\
\text { FDL_Low }- \text { FDL_high } \\
\text { MHz }\end{array}$ & $\begin{array}{c}\text { Bandwidth } \\
\text { MHz }\end{array}$ & $\begin{array}{c}\text { Obtained } \\
\text { FDL_Low - FDL_high } \\
\text { MHz }\end{array}$ & $\begin{array}{c}\text { Obtained bandwidth of } \\
\text { the proposed antenna } \\
\text { MHz }\end{array}$ \\
\hline $\begin{array}{c}\text { LTE 42 } \\
\text { (uplink and downlink) }\end{array}$ & $3400-3600$ & 200 & $3486-3598$ & 112 \\
$\begin{array}{c}\text { LTE 22 } \\
\text { (downink) }\end{array}$ & $3510-3590$ & 80 & $3510-3590$ & 80 \\
\hline
\end{tabular}

Figure 3 shows the 3D radiation pattern of the antenna at $3533 \mathrm{MHz}$. Good radiation pattern is obtained in the horizontal plane. Figure $4 \mathrm{a} \& \mathrm{~b}$ shows the $2 \mathrm{D}$ radiation pattern at $\varphi=0$ and $\theta=90$. It can be seen that the antenna performance is good and more radiation occurs at this frequency. For the merely obtained omnidirectional radiation pattern, the antenna can be used for small cell wireless communication. Figure 5 shows the simulation VSWR of the proposed antenna. VSWR value of 1.09 obtained is within the performance limit. Gain and Directivity are $6.6 \mathrm{~dB}$ and $7.8 \mathrm{dBi}$ respectively.
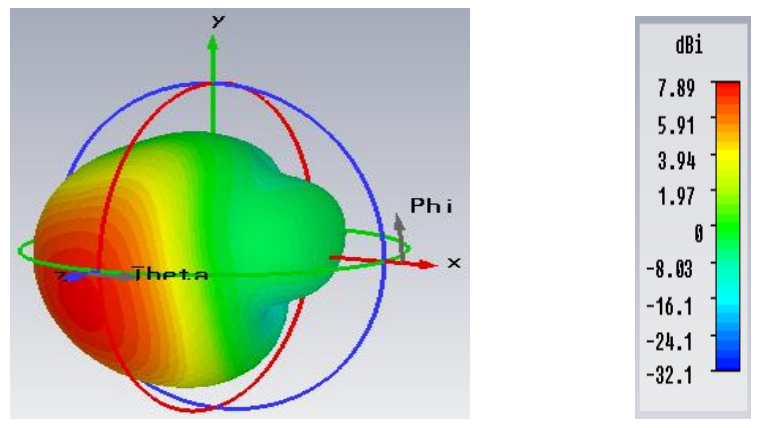

Figure 3. Simulation 3D radiation pattern of the antenna at $3533 \mathrm{MHz}$

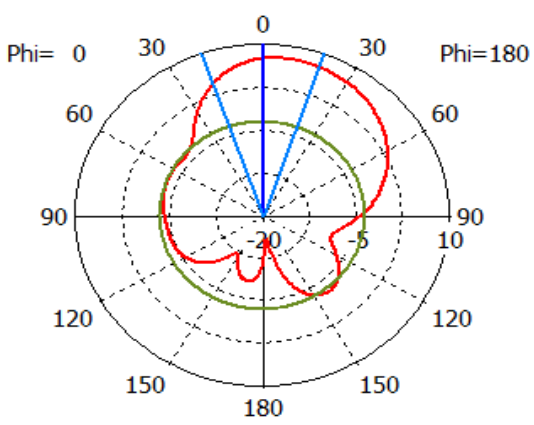

(a)

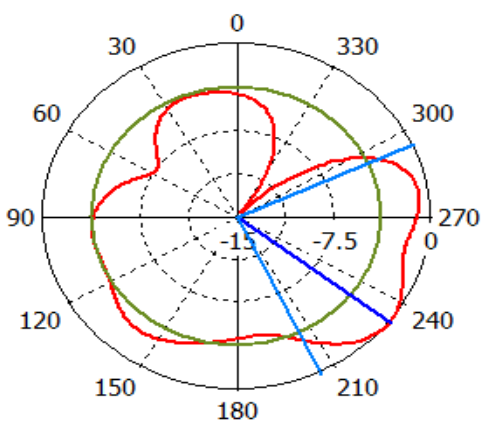

(b)

Figure 4. Simulation 2D radiation pattern of the proposed antenna at $3533 \mathrm{MHz}$ a) $\varphi=0$, b) $\theta=90$ 
Emphasize on $3500 \mathrm{MHz}$ is advantageous for the antenna designed in this band. $3500 \mathrm{MHz}$ is one of the important bands of global spectrum for small cell. $3500 \mathrm{MHz}$ has many band characteristics adapt to dense "small cells" for offloading traffic a) high bandwidth: to fulfill the requirement of increasing capacity, b) high propagation loss: well suited for small cell coverage, c) reduced coverage capability: to help the interference management associated with dense cellular [11].

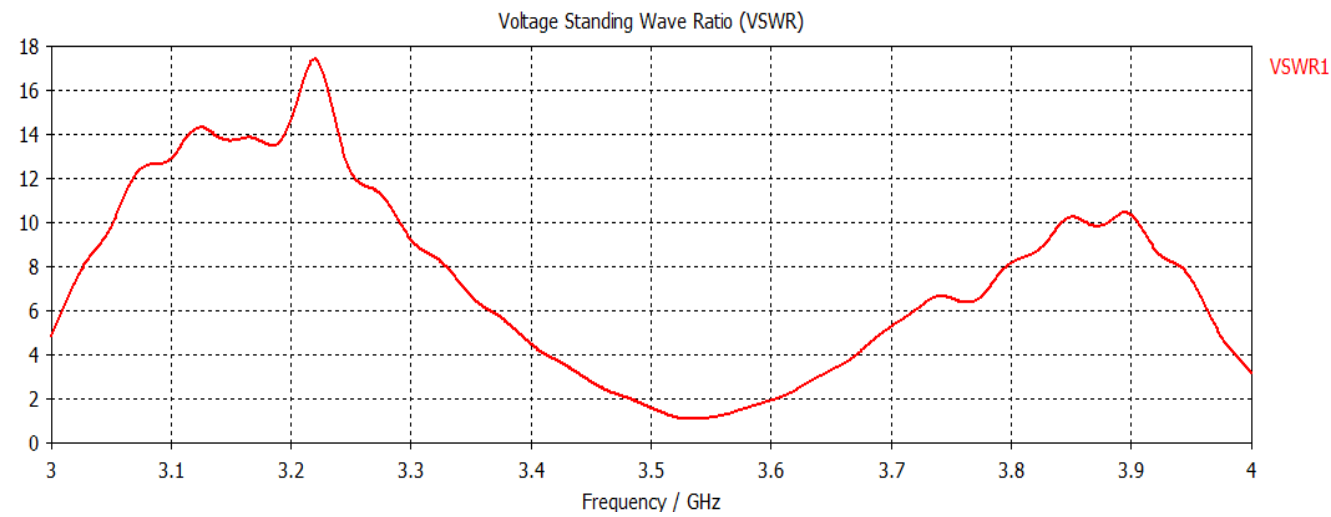

Figure 5. Simulated VSWR of the proposed antenna

This band has great potential to become a globally harmonized band with atleast $50 \mathrm{MHz}$ allocated [11]. The current distribution on the metallic surface of the antenna is well visualized for its characteristic as shown in Figure 6. The folded strip provides longer resonance path at this frequency corresponding to the radiation.
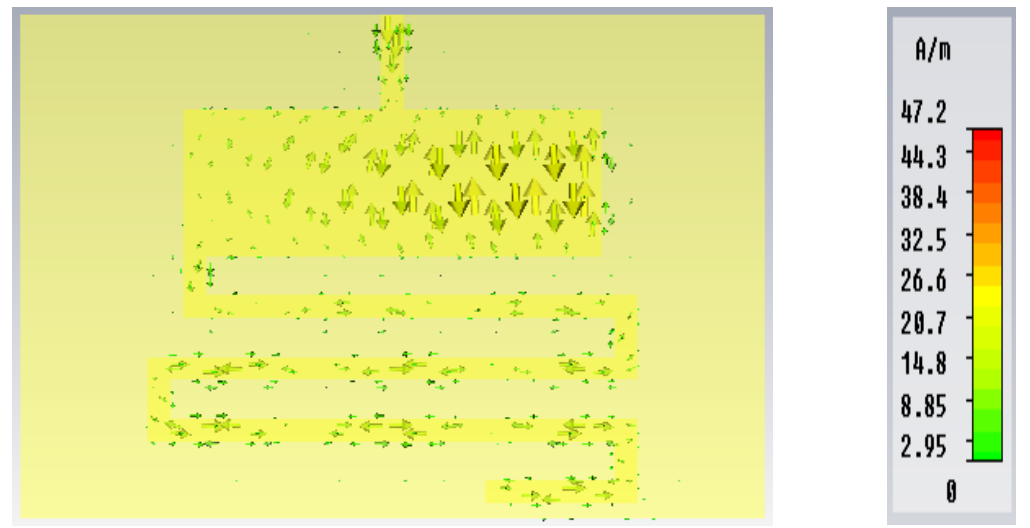

Figure 6. Simulated current densities on the metallic surface of the proposed antenna

\section{CONCLUSION}

A simple and cost effective novel approach to design the meandered line antenna is presented in this paper. Antenna operates at both LTE 42 / LTE 22 downlink frequency band. For the obtained broadband performance of $112 \mathrm{MHz}$ bandwidth, gain and directivity, the meandered monopole antenna is found suitable to exploit in small cell coverage, LTE Hotspot and Indoor enhancement solutions. Also, obtained radiation pattern and efficiency are advantageous to incorporate the antenna in LTE devices. Due to the bandwidth hungry applications and the requirement of the broadband spectrum, $3533 \mathrm{MHz}$ finds trend as one of the important bands to concentrate on interference management associated with dense cellular areas. Thus considering the advantageous of the structure and the operating band, the proposal can be treated as the capability of the antenna as a reliable design approach for LTE communication devices. 


\section{ACKNOWLEDGEMENTS}

Thanks to Dr. N. Amutha Prabha, senior professor, School of Electrical Engineering, VIT University, for allowing me to use her personal system at time even when she want to use it to collect the intellectual property. Personally i thank her for helping me without which this work would haven't been done earlier.

\section{REFERENCES}

[1] Kuldeep Kumar Parashar, "Design and Analysis of I-slotted Rectangular Microstrip Patch Antenna for Wireless Application", International Journal of Electrical and Computer Engineering, Vol. 4, pp. 31-36, Feb 2014.

[2] Hemn Younesiraad, Mohammad Bemani, Saied Nikmehr, "Small Multi-band Rectangular Dielectric Resonator Antennas for Personal Communication Devices," International Journal of Electrical and Computer Engineering, Vol. 4, pp. 1-6, Feb 2014

[3] Shao-Li Zuo, Zhi-Ya Zhang, and Jia-Wei Yang, "Planar Meander Monopole Antenna with Parasitic Strips and Sleeve Feed for DVB-H/LTE/GSM850/900 Operation in Mobile Phone", IEEE Antennas and Wireless Propagation Letters, Vol. 12, pp. 27-30, 2013.

[4] C. C. Hsu, H. H. Song, "Design, Fabrication, and Characterization of a Dual-Band Electrically Small Meander-line Monopole Antenna for Wireless Communications", International Journal of Electromagnetics and Applications, Vol. 3, No. 2, pp. 27-34, 2013.

[5] Yuan Yao, Xing Wang, and Junsheng Yu, "Multiband Planar Monopole Antenna for LTE MIMO Systems", International Journal of Antennas and Propagation, Hindawi Publishing Corporation, 2012.

[6] Rashid Ahmad Bhatti, Soongyu Yi, and Seong-Ook Park, "Compact Antenna Array With Port Decoupling for LTE-Standardized Mobile Phones", IEEE Antennas and Wireless Propagation Letters, Vol. 8, pp. 1430-1433, 2009.

[7] Leonardo Lizzi, Andrea Massa, "Dual-Band Printed Fractal Monopole Antenna for LTE Applications", IEEE Antennas and Wireless Propagation Letters, Vol. 10, pp. 760-763, 2011.

[8] Wen-Yi Tsai, I-Fong Chen, Chia-Mei Peng, Pei-Cheng Hu, Hsu-Hung Tung, and Hsuan-Chi Lin, "Broadband Fractal Circular-monopole Antenna", PIERS Proceedings, Marrakesh, MOROCCO, March 2011.

[9] C.-W. Chiu and C.-H. Chang, "A Meandered Loop Antenna for LTE/WWAN Operations in a Smart Phone", Progress in Electromagnetics Research C, Vol. 16, pp. 147-160, 2010.

[10] G. Zhao, F.-S. Zhang, Y. Song, Z.-B. Weng, and Y.-C. Jiao, "Compact Ring Monopole Antenna With Double Meander Lines For 2.4/5 GHz Dual-Band Operation", Progress in Electromagnetics Research, PIER 72, pp. 187194, 2007.

[11] www.huawei.com/ilink/en/download/HW_204545. 